\title{
Nanotechnological Developments in Structural Design: Load-Bearing Materials
}

\author{
Zeynep Yesim Ilerisoy \\ Architecture Department \\ Faculty of Architecture, Gazi University \\ Ankara, Turkey \\ zyharmankaya@gazi.edu.tr
}

\author{
Yenal Takva \\ Architecture Department \\ Faculty of Architecture, Gazi University \\ Ankara, Turkey \\ yenal.takva@gazi.edu.tr
}

\begin{abstract}
Nanotechnology has a wide field of possible applications that includes the design, manufacture and application of nanomaterials and nanostructures. The selection of materials is an issue of significant importance to the construction industry. Concrete, steel and wood materials are considered as the main load-bearing materials in building construction and due to nanotechnological developments advanced application possibilities have been provided. The aim of this study is to systematically examine the nanotechnological developments on concrete, steel and wood which are used as load-bearing materials. The materials' properties and the steps that enable these properties are considered and the advantages brought by the use of nanotechnology are tabulated. The differences in the molecular level of materials exhibiting behaviors different from those of conventional scale equivalents are shown.
\end{abstract} wood

Keywords-architecture; load-bearing system; concrete; steel;

\section{INTRODUCTION}

Considered as the industrial revolution of the 21 st century, nanotechnology is related to controlling the materials in very small dimensions [1] and has become one of the fastest growing industrial sectors in the world with an impact to a vast variety of science and technology fields such as materials, medical sciences, computers, textiles, economics, environment, sustainable energy, etc. The incorporation of nanotechnology into future plans of major industrial countries emphasizes the importance that nanotechnology represents in terms of power and wealth of those countries in the near future [2]. Multifunctional and smart materials that are rapidly developed can be employed to add extraordinary features to building materials. Nanotechnology contributes to many features such as maximizing the quality and performance of existing products, extending physical life by preventing material damage, reducing material weight or volume, reducing the number of manufacturing steps by improving production methods, ensuring production with more efficiently usable materials, minimizing the operating costs of maintenance and repair [3]. Nanotechnology is the creation of materials and devices by providing control of the material at atomic, molecular and nano level (one billionth of a meter) [4]. In other words, it is using very small particles of material to obtain new, large materials [5]. The term "nanomaterials" is emerging as a general name given for such materials. Some examples of improved nanomaterials include copper which is normally opaque but it becomes translucent at nano-level, silicon that is an insulator at the macro level but conductive at nano-level and gold which normally doesn't react with anything at macro level but it transforms into a very active element in nano-level [6].

There are two main objectives in developing new nanomaterials. The first is to make use of the different properties of nano materials developed using special production techniques; and the second is to manipulate the inner structures of largescale materials at the atomic level and to control them, therefore giving them extraordinary properties [6]. In this direction, there are two main approaches in the production of nanomaterials aiming to form functional structures with individual atoms and molecules. The first approach, which is used to produce nano-scale structures from top to bottom, involves the process of separating the material in its entirety into small pieces. The entire material is reduced to a nanometer scale and miniaturized by chemical abrasion methods. The second approach, which is characterized as from bottom to top, is the process of dimensionally growing material atoms and molecules by chemical synthesis methods [7].

The architecture, engineering and construction sectors collectively represent a broad application area of nanotechnology and nanomaterials. Such materials when used as load-bearing system materials exhibit different behaviors from those of conventional scale equivalents, thus creating new possibilities in the construction industry, which are further discussed in this paper.

\section{NANOMATERIALS IN THE CONSTRUCTION INDUSTRY}

The choice of materials in the construction sector is of great importance. Advances in nanomaterials have brought forward innovations that improved the performance of buildings and infrastructure facilities. Through nanotechnology, building materials have gained features such as higher strength, durability, permanent and quick constructability and environmental impact reduction. 


\section{A. Concrete}

Concrete, which is a cement based and multi-phase composite material and have been widely used for many years, are gaining important new features with the use of carbon nanotubes and nanoparticles. Carbon nanotubes are graphite planes wrapped around pipes and have a cylindrical surface containing regular hexagons with carbon atoms at their corners [8]. Carbon nanotubes have superior properties such as surface chemistry and high stability due to its higher conductivity than copper, elastic deformation and durability stronger than steel [9]. Carbon nanotubes, ranging in length from about a few micrometers to 550 micrometers and ranging in diameter from about 1 to $50 \mathrm{~nm}$, are in the form of cylinders and are classified as single (SWCNT) or multilayer (MWCNT). Adding carbon nanotubes to the cement in a small amount significantly improved the mechanical properties of the concrete [8]. Multilayered nanotubes provide the highest increase in compressive strength and bending strength of concrete. They have yielded an advantage of $+25 \mathrm{~N} / \mathrm{mm} 2$ in compressive strength and +8 $\mathrm{N} / \mathrm{mm} 2$ in bending strength compared with conventional samples [10].

Nanoparticles can be defined as particles whose size ranges from 1 to $100 \mathrm{~nm}$ [6]. The first of these particles used to improve concrete material properties is titanium dioxide (Tİ2). In most applications, the concrete surface is exposed to liquids such as water, mineral solutions, oil, solvents, etc., which results in wear, exposure to environmental influences, and erosion. When dry concrete is exposed to liquid, most of the fluids are absorbed by the pores due to capillary forces. For this reason, it is important to synthesize concrete with water repellent property in order to increase the durability [11]. TiO2 is a white pigment that can be used as a reflective coating material that can decompose organic pollutants and volatile organic compounds by strong photocatalytic reactions. It reduces airborne contaminant concentration when used outside the building. TiO2 is a hydrophilic material that allows the surface to be cleaned and used to keep the whiteness and gloss of the material for a long time [12].

Another nanoparticle used in concrete is silica. This compound, with the chemical formula $\mathrm{SiO} 2$, is crystal-like, just like diamond. This material, which is found abundantly in the earth's crust, has a relatively high melting and boiling point and exists in two forms in nature, as crystalline and amorphous. The production of high quality concrete depends on the type and size of the silicon particles. Adding this nanoparticle into the cement mortar makes the compressive and bending strength of the cement mortar better than conventional mortar. In the concrete material, it ensures the control of the CSH (calciumsilicate-hydrate) dissociation reaction and increases the strength of the concrete by preventing the water from penetrating into the concrete [13].

Another nanoparticle used in the concrete industry is nano amorphous silica. Amorphous silica is one of the allotropes of silicon. It is an important material used primarily for increasing adherence and obtaining high performance concrete. The other advantages that it provides to concrete can be listed as resistance against abrasion, non-slip surface acquisition, resistance to fire and anti-reflective properties.
Concrete is a brittle material and its repair in case of cracking can be very difficult. However, latest studies used bacteria to repair cracks in the material so that concrete was able to renew itself. In this method, the concrete is renewed with the help of a special bacteria that can live in the alkaline (basic) concrete environment within nature. An example of these bacteria is known as Bacillus, which lives in alkaline lakes in Russia and Egypt. These bacteria are embedded in small ceramic trenches and are incorporated into the wet concrete mix. Staying dormant in concrete, these bacteria become active with the increase of cracks and water leaks. The resulting calcium carbonate from their reactions penetrates into the cracks and closes the pores. By adding the anaerobic microorganisms used in this application to the mixture of water and concrete, the resistance of 28 days cured concrete increases by $25 \%[12]$.

\section{B. Steel}

Steel is one of the most important materials widely used in the building industry. Its properties such as strength, corrosion resistance and weldability are very important in design and construction [14]. Fatigue under constant load creates deformations in the material. Increased tension causes cracking. In this case, the physical life of materials used in the construction is reduced. Research has shown that the use of copper nanoparticles reduces cracking caused by fatigue. It is also revealed that the addition of copper nanoparticles to the steel prevented the stresses and corrosion effects from the pressure-induced stress [15]. The steel produced with these nanoparticles has been used primarily in the building industry and bridges. In addition to the increase in durability, surface roughness is reduced and features of fingerprint remnant prevention and anti-corrosion properties are also obtained.

It is important to ensure sufficient strength at the connection points used to connect the different load-bearing system components to each other in steel structures. Concerning this issue, nanoparticles of vanadium and molybdenum reduce fracture problems and hydrogen brittleness at the connection points with the use of high strength bolts, and allow cracking problems to be postponed [16]. When it is considered that the welded parts are fragile, the strength of these parts under dynamic loads is increased by using magnesium and calcium nanoparticles [17]. In particular, carbon nanotubes can be used to strengthen high strength steel cables used in suspension bridge constructions. The use of strong cables in the buildings reduces construction costs and saves time. Nano scale strong cables were produced in conducted studies by using phase correction cementite ( $\mathrm{Fe} 3 \mathrm{C}$ ). The use of $\mathrm{TiO} 2$ has also led to a major transformation in the manufacture of nano-wires, nano-coatings and bolts used in construction [12]. The increase in yield strength increases the physical life of steel material. Oxides which are commonly used in spray coating techniques are used to increase yield strength. The alloys used increase the yield strength of the steel 100 times. The alloy uses carbon-nitrite alloy containing yttrium oxide nanoparticles $[14,15]$. In addition, stainless steel castings have been produced in nanotechnology using different compounds such as manganese, nitrogen and niobium carbide. The steel produced with this method has high heat tolerance. 
Finally, the MMFX2 steel, obtained by modifying the conventional steel microstructure, is three times stronger than conventional steel, more flexible, has higher strength and higher resistance to corrosion [12]. In this product, the formation of microgalvanic cells, which have a significant contribution to accelerating the corrosion activity in material composition and production processes, is minimized [15]. Increasing the resistance to corrosion has made the use of this material economically more advantageous. The properties of this modified steel can be summarized as being cheaper than ordinary steel, more malleable, having better energy absorptive properties and higher durability .

\section{Wood}

Wood is a living material used as a daily building material from the past ages to present day and consists of nanotube or nano fibrillation. The lignocellulosic structure (woody texture) formed by the combination of lignin and cellulose, which strengthen plant cells, is extremely strong. Nanoscale lignocellulosic surfaces create new opportunities for appropriate for self-cleaning surfaces, self-repairing features, high-level water repellent coatings containing silica and alumina nanoparticles, and wood materials with hydrophobic polymers [1, 18]. With nanotechnology, scientists aim to control fiber bonding at the microscopic level and improve the structural performance and usability of the wood by providing nanofiber bonding. Nanotechnology can reduce or eliminate the occurrence of random defects that limit the performance of wood. Nanocatalysts that trigger chemical reactions and make the wood more functional than its current properties make these reactions faster, easier and more effective. In addition, natural nanoparticle insecticides and repellents, self-cleaning wood surfaces, and nanosensors that define photocatalytic degradation of contaminants are at the forefront of nanotechnological uses in wood materials [19].

\section{APPLiCATION AND EVALUATION}

The construction sector is one of the most prominent application area of nanotechnology. According to [20], the construction sector is the primary potential consumer of nanostructured materials, although many materials have not yet cleared the laboratory phase. Table I compares the advantages of the nanoparticles used in the nanotechnological production process on the load-bearing materials. Nanomaterials' advantages can be summarized as follows:

- In case of concrete: self-repair, faster stiffening and hydration, high strength, reduction of air pollutant concentration, easy cleaning and self-cleaning, water repellent property, resistance against fire and abrasion.

- In case of steel: cracking and corrosion control, fingerprinting, high ductility and yield strength, high heat tolerance, better weldability and high strength steel cable production, as well as high resistance to fire, delayed cracking problems in high strength screws, high flexibility and scratch resistance.
- In case of wood: rot retardancy, water repellency, preservation of color, fire protection, easy cleaning and selfcleaning.

TABLE I. PROPERTIES OF DIFFERENT NANOMATERIALS

\begin{tabular}{|c|c|c|c|c|}
\hline 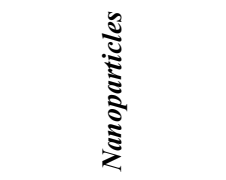 & Property & 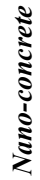 & 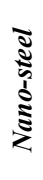 & $\begin{array}{l}\overline{5} \\
\vdots \\
\vdots \\
\vdots \\
\vdots \\
\vdots \\
\vdots\end{array}$ \\
\hline \multirow{3}{*}{ SİO2 } & $\begin{array}{c}\text { Self-repair } \\
\text { Faster stiffening } \\
\text { Faster hydration } \\
\text { High strength } \\
\end{array}$ & $\sqrt{ }$ & & \\
\hline & $\begin{array}{c}\text { Rot retardancy } \\
\text { Water repellency }\end{array}$ & & & $\sqrt{ }$ \\
\hline & Resistance against fire & & $\sqrt{ }$ & $\sqrt{ }$ \\
\hline CNT & High strength & $\sqrt{ }$ & & \\
\hline \multirow{3}{*}{ TİO2 } & $\begin{array}{c}\text { Reduction of air } \\
\text { pollutant concentration }\end{array}$ & $\sqrt{ }$ & & \\
\hline & $\begin{array}{l}\text { Easy cleaning, Self- } \\
\text { cleaning } \\
\text { Water repellent property }\end{array}$ & $\sqrt{ }$ & & $\sqrt{ }$ \\
\hline & $\begin{array}{l}\text { Preservation of color } \\
\text { Fire protection }\end{array}$ & & & $\sqrt{ }$ \\
\hline $\begin{array}{l}\text { Nano Amorphous } \\
\text { Silica }\end{array}$ & $\begin{array}{c}\text { Resistance against fire } \\
\text { Resistance against } \\
\text { abrasion }\end{array}$ & $\sqrt{ }$ & & \\
\hline $\begin{array}{l}\text { Vanadium } \\
\text { Molybdenum }\end{array}$ & $\begin{array}{l}\text { Delayed cracking } \\
\text { problems in high } \\
\text { strength screws }\end{array}$ & & $\sqrt{ }$ & \\
\hline Copper & $\begin{array}{c}\text { High flexibility } \\
\text { Scratch resistance } \\
\text { Cracking and corrosion } \\
\text { control } \\
\text { Fingerprinting } \\
\end{array}$ & & $\sqrt{ }$ & \\
\hline $\begin{array}{l}\text { Carbon-Nitrite } \\
\text { Alloy }\end{array}$ & $\begin{array}{l}\text { high ductility and yield } \\
\text { strength }\end{array}$ & & $\sqrt{ }$ & \\
\hline $\begin{array}{c}\text { Manganese, } \\
\text { Nitrogen Niobium } \\
\text { Carbide }\end{array}$ & High heat tolerance & & $\sqrt{ }$ & \\
\hline $\begin{array}{l}\mathrm{Mg} \\
\mathrm{Ca}\end{array}$ & Better weldability & & $\sqrt{ }$ & \\
\hline $\begin{array}{l}\text { Phase Correction } \\
\text { Cementite } \\
(\mathrm{Fe} 3 \mathrm{C})\end{array}$ & High strength steel cable & & $\sqrt{ }$ & \\
\hline Alumina & Rot retardancy & & & $\sqrt{ }$ \\
\hline
\end{tabular}

\section{CONCLUSION}

Nanotechnology can be used to provide significant improvements to the properties of materials widely used in the construction industry, such as concrete, steel and wood. Along with maximizing the quality and performance of existing products, they contribute to many criteria such as extending the physical life by preventing damage to materials, providing production with more efficient use of materials, minimizing operating or maintenance-repair needs. Along with the fact that nanotechnology produced products have unique characteristics; significant reduction of existing construction problems, the shortening of construction time and effecting the long-term costs are also possible. In professional terms, these progresses should be followed carefully. 


\section{REFERENCES}

[1] A. S. Y. Mohamed, "Nano-innovation in construction, a new era of sustainability, International Conferance on Environment And Civil Engineering ( ICEACE’2015) Pattaya, Thailand, April 24-25, 2015

[2] A. Mnyusiwalla, A. S. Daar, P. A. Singer, “'Mind the gap': Science and ethics in nanotechnology", Nanotechnology, Vol. 14, No. 3, 2003

[3] S. Leydecker, Nano Materials in Architecture, Interior Architecture and Design, Birkhauser, Boston, 43, 2008

[4] IWGN Workshop Report, Nanotechnology Research Directions: Vision for Nanotechnology R\&D in the Next Decade, IWGN Research Report, Committee on Technology, Interagency Working Group on Nanoscience, Engineering and Technology (IWGN), National Science and Technology Council, USA, 1999

[5] ISO/TS 800004-1 Nanotechnologies—Vocabulary—Part 1: Core terms. Geneva, 2011

[6] S. Gullapalli, M. S. Wong, "Nanotechnology: a guide to nano-objects", Chemical Engineering Progress, Vol. 107, No. 5, pp. 28-32, 2011

[7] B. Gordijn, "Nanoethics: from utopian dreams and apocalyptic nightmares towards a more balanced view", Science and Engineering Ethics, Vol. 11, No. 4, 521-533, 2005

[8] X. Wang, Q. Li, J. Xie, Z. Jin, J. Wang, Y. Li, K. Jiang, S. Fan, "Fabrication of ultralong and electrically uniform single-walled carbon nanotubes on clean substrates", Nano Letters, Vol. 9, No. 9, pp. $3137-$ 3141,2009

[9] J. Lee, S. Mahendra, P. J. J. Alvarez, "Nanomaterials in the construction industry: a review of their applications and environmental health and safety considerations", ACS Nano, Vol. 4, No. 7, pp. 3580-3590, 2010

[10] K. A. Alsafar, "Review of the use of nanotechnology in construction industry", International Journal of Engineering Research And Development, Vol. 10, No. 8, pp. 67-70, 2014

[11] Y. Kothari, S. Dewalkar, "Application of Nanotechnology in Smart Civil Structures", International Journal of Technical Research and Applicatons Vol. 4, No. 3, pp. 13-17, 2016

[12] A. Kazempour, "The impact of nanotechnology in reinforced structures: the structure of concrete and steel", Journal of Current Research in Science, Vol. S(1), pp. 421-430, 2016

[13] T. Ji, "Preliminary study on the water permeability and microstructure of concrete incorporating nano-SiO2", Cement and Concrete Research, Vol. 35, No. 10, pp. 1943-1947, 2005
[14] A. Khitab, M. T. Arshad, "Nano construction materials: review", Reviews on Advanced Materials Science, Vol. 38, pp. 181-189, 2014

[15] Saurav, "Application Of Nanotechnology In Building Materials", International Journal of Engineering Research and Applications, Vol. 2, No. 5, pp.1077-1082, 2012

[16] R. Olar, "Nanomaterials And Nanotechnologies For Civil Engineering, Buletinul Institutului Politehnic Din Iasi, Vol. LIV (LVIII), No. 4, pp. 109-117, 2011

[17] A. Shakibabarough, M. Valinejadshoubi, M. Valinejadshoubi, "Useable and precautionary aspect of using nanotechnology and nano-materials in the construction industry", International Journal of Science, Engineering and Technology Research, Vol. 3, No. 4, pp. 841-848, 2014

[18] P. Khandve, "Nanotechnology for building material", International Journal of Basic and Applied Research, Special Vol. 04, pp. 146-151, 2014

[19] V. Pents, "Application of nanotechnology in building materials", available at: http://civilpents.blogspot.gr/2012/10/application-ofnanotechnology-in.html

[20] P. J. M. Bartos, "Nanotechnology in Construction: A Roadmap for Development", Proceedings of the 2nd International Symposium on Nanotechnology in Construction, Bilbao, Spain, 27-36, 2005 